\title{
Design of experiment for the optimisation of deep reactive ion etching of silicon inserts for micro-fabrication
}

\author{
K. Wallis", C.P. Shaw and J.R. Alcock \\ Cranfield University, Cranfield, Bedfordshire, MK43 0AL, UK
}

\begin{abstract}
The following paper describes a design of experiments investigation of the deep reactive of pillar structures on a silicon wafer. The etched wafers would subsequently be used as masters for the fabrication of nickel mould inserts for microinjection moulding.

Undercuts occur when the pillar base has a smaller cross-section than the apex of the pillar. They therefore affect tolerances of the subsequent nickel mould, its strength and its de-mouldability from the silicon form.

The response measured in these experiments was the degree of undercut of micro-scale (10 $\mu \mathrm{m} \times 10 \mu \mathrm{m} \times 40 \mu \mathrm{m}, 5 \mu \mathrm{m}$ x $5 \mu \mathrm{m}$ x $40 \mu \mathrm{m}$ and $2 \mu \mathrm{m}$ x $2 \mu \mathrm{m}$ x $40 \mu \mathrm{m})$

The literature suggests that gas pressure, platen power, gas flow rate, phase switching times and mask size can all affect the degree of undercut. After examination of this literature, and of manufacturers guidelines, three parameters were selected for experimental testing: platen power, $\mathrm{C}_{4} \mathrm{~F}_{8}$ gas flow rate during the passivation phase and switching times.

Switching times was found to be the only statistically significant parameter for both $10 \times 10 \mu \mathrm{m}$ and $5 \times 5 \mu \mathrm{m}$ pillars. The $2 \times 2 \mu \mathrm{m}$ pillars were not successfully replicated and could therefore not undergo statistical evaluation.
\end{abstract}

\section{KEY WORDS LIST}

Deep reactive ion etching, photolithography, microfabrication, design of experiment, platen power, $\mathrm{C}_{4} \mathrm{~F}_{8}$ gas flow, switching times, undercut

\section{INTRODUCTION}

Undercuts, where the dimensions of the features are smaller at the base than at the apex, to surface features are an issue which needs to be examined when fabricating surfaces designed to be used in further processes. For example if the surface is to be used as a mould insert then undercuts can affect the accuracy of the replicate and in extreme cases render the mould de-mouldable.

Deep reactive ion etching (DRIE) is an anisotropic etching process used to fabricate surface features with vertical sidewalls in silicon. Using a time-multiplexed etching process ${ }^{1 ; 2}$, in which a combination of etching and the deposition of a protective passivation layer is used, vertical etching of a sample can be controlled. This process is known as the Bosch process, in which the wafer is subjected to alternate etching and passivation phases and the silicon surface can be etched with micro-scale features with vertical sidewalls. The Bosch process produces these vertical sidewalls by continuously alternating between an etching phase and a passivation phase, resulting in an anisotropic etch pattern, Figure 1.

\footnotetext{
* K. Wallis

Cranfield University, Building 56, Cranfield, Bedfordshire, MK43 0AL, UK

e-mail: k.wallis@cranfield.ac.uk
}

\footnotetext{
Micromachining and Microfabrication Process Technology XVII, edited by Mary Ann Maher, Paul J. Resnick, Proc. of SPIE Vol. 8248, 824808 · (c) 2012 SPIE · CCC code: 0277-786X/12/\$18 · doi: 10.1117/12.906772
} 


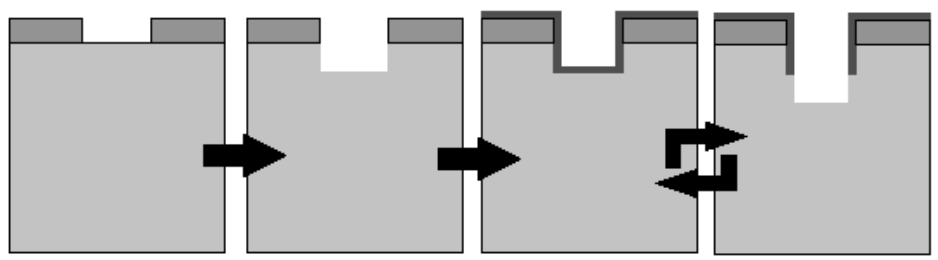

(a)

(b)

(c)

(d)

Figure 1, DRIE Bosch Process (a) Silicon wafer with photoresist, (b) Anisotropic etching phase, (c) Passivation phase, (d) Second anisotropic etching phase ${ }^{3}$

During the etching phase the silicon wafer is etched by directional bombardment with plasma ions. $\mathrm{SF}_{6}$ gas is most commonly used when etching silicon. For the passivation phase the etched silicon is coated in a chemically inert layer. $\mathrm{C}_{4} \mathrm{~F}_{8}$ gas is used to produce this inert layer when etching silicon, which protects the surface from further etching.

During the subsequent etching phase, due to the directional bombardment of plasma ions, the passivation layer at the base of the etched features is sputtered away and further etching of the silicon will continue in an orthogonal direction ${ }^{4}$. Only the passivation layer at the base of the etched features is removed, the sidewalls of the feature remain coated in the protective layer, which results in highly anisotropic sidewalls. Each phase lasts only a few seconds and the alternation between the two continues for a pre-set period of time until the desired etch depth is reached.

The literature suggests that several parameters which can affect the production of undercuts to surface features during DRIE notably: Pressure ${ }^{2 ; 5-7}$, platen power ${ }^{2 ; 8}$, gas flow ${ }^{7-9}$, switching times ${ }^{7 ; 9}$ and mask size ${ }^{9}$.After examination of this literature and of manufactures guidelines ${ }^{10}$ three parameters were selected for experimental testing: platen power, $\mathrm{C}_{4} \mathrm{~F}_{8}$ gas flow in the passivation phase and switching times between phases. Platen power has a large influence on etch rate ${ }^{2 ; 8}$, according to Evans \& Beheim ${ }^{2}$ when a high platen power is combines with high pressure during the etching phase the anisotropic nature of the profile is improved.

Altering the switching times, the ratio between the etching and passivation phases, has been found a major effect on the etch profile and presence of undercuts. As shown in Figure 2, the proposed mechanism is that by increasing the etch time the likelihood of a negative etch profile, and therefore undercuts, is increased. Whereas if the passivation rate is increased the thickness of the passivation layer is also increased resulting in a reduced etch rate and a more positive etch profile $^{2}$, Figure 2.

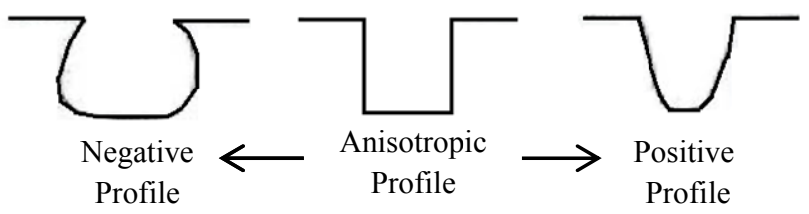

Figure 2, Schematic of etch profiles

Alterations to the $\mathrm{C}_{4} \mathrm{~F}_{8}$ gas flow in the passivation phase have been found to effect the production of a more positive etch profile ${ }^{10}$ due to the increased thickness of the passivation layer.

The aim of this paper is to examine the effect of these factors on the undercut sustained by the various pillar features during the DRIE process. Pillar features of $10 \times 10 \mu \mathrm{m}, 5 \times 5 \mu \mathrm{m}$ and $2 \times 2 \mu \mathrm{m}$ were used. 


\subsection{Experimental Design}

\section{METHOD}

The deep reactive ion etching process was investigated using a design of experiment (DOE) approach. The DOE approach to process optimisation was developed as a statistical method capable of highlighting the interactions between various factors to determine the optimum levels required for experimental work ${ }^{11}$. As well as being more practical regarding time and resources when compared to methods which focus on the alteration of a single factor per run, the DOE approach also provides a route to observe how various factors may interact to affect the response ${ }^{12}$.

The factor levels used for this DOE are displayed in Table 1. The criteria for the selection of these levels are explained in Table 2.

\begin{tabular}{ccc}
\hline Factor & Low Level & High Level \\
\hline Platen Power $(\mathrm{W})$ & 10 & 18 \\
\hline $\mathrm{C}_{4} \mathrm{~F}_{8}$ Gas Flow in Passivation \\
$\begin{array}{c}\text { Stage }\left(\mathrm{sccm}^{\dagger}\right) \\
\begin{array}{c}\text { Switching times }- \text { Etching: } \\
\text { Passivation (s:s) }\end{array}\end{array}$ & 70 & 100 \\
\hline Table 1, Factor exaned & $5: 5$ & $9: 5$ \\
\hline
\end{tabular}

Table 1, Factor examined; high and low levels

\begin{tabular}{|c|c|c|}
\hline Factors & Low Level & High Level \\
\hline Platen Power (W) & $\begin{array}{l}\text { The minimum value at which ion } \\
\text { directionality could be controlled for } \\
\text { the scale of the features examined - } \\
\text { taking into account equipment } \\
\text { limitations }\end{array}$ & $\begin{array}{l}\text { The maximum value at which ions } \\
\text { directionality could be controlled for } \\
\text { the scale of the features examined - } \\
\text { taking into account equipment } \\
\text { limitations }\end{array}$ \\
\hline $\begin{array}{c}\mathrm{C}_{4} \mathrm{~F}_{8} \text { Gas Flow in Passivation } \\
\text { Stage }(\mathrm{sccm})\end{array}$ & $\begin{array}{l}\text { The minimum value for obtaining a } \\
\text { sufficient passivation layer after } \\
\text { consideration of the passivation layer } \\
\text { required and system pressure - taking } \\
\text { into account equipment limitations }\end{array}$ & $\begin{array}{l}\text { The maximum value at which deposited } \\
\text { passivation layer would not hinder } \\
\text { etching of features after consideration } \\
\text { of the passivation layer required and } \\
\text { system pressure - taking into account } \\
\text { equipment limitations }\end{array}$ \\
\hline $\begin{array}{l}\text { Switching Times - Etching: } \\
\text { Passivation (s:s) }\end{array}$ & $\begin{array}{l}\text { The minimum level chosen due to } \\
\text { feature dimensions and passivation } \\
\text { layer thickness (if the etching time is } \\
\text { too short, in comparison to the } \\
\text { passivation time, it will not completely } \\
\text { remove the passivation layer and the } \\
\text { likelihood of the uneven etching } \\
\text { increases) }\end{array}$ & $\begin{array}{l}\text { The maximum level chosen after taking } \\
\text { into account the dimensions of the } \\
\text { features and the effect on the } \\
\text { passivation layer (if the etching time is } \\
\text { too long, in comparison to the } \\
\text { passivation time, it will quickly remove } \\
\text { the passivation layer and begin to } \\
\text { isotropically etch the silicon) }\end{array}$ \\
\hline
\end{tabular}

Table 2, Reasons for DOE levels selected

The DOE scheme used was devised using a full factorial 8 run design generated using Minitab ${ }^{\circledR} 15$. The order of the DOE runs, Table 3, was generated using a built-in randomizer function in Minitab.

${ }^{\dagger}$ sccm: standard cubic centimetre per minute 


\begin{tabular}{cccc}
\hline Run & $\begin{array}{c}\text { Platen Power } \\
(\mathrm{W})\end{array}$ & $\begin{array}{c}\mathrm{C}_{4} \mathrm{~F}_{8} \text { Gas Flow in } \\
\text { Passivation Stage }(\mathrm{sccm})\end{array}$ & $\begin{array}{c}\text { Switching Times }- \\
\text { Etching: Passivation (s:s) }\end{array}$ \\
\hline 1 & - & + & - \\
\hline 2 & + & + & + \\
\hline 3 & - & + & + \\
\hline 4 & - & - & + \\
\hline 5 & + & - & - \\
\hline 6 & + & + & - \\
\hline 7 & + & - & + \\
\hline 8 & - & - &
\end{tabular}

The response examined was the undercut of the features, Figure 3, and was calculated using equation 1 . Where $\mathrm{W}_{1}$ is the width of the pillar apex, $\mathrm{W}_{2}$ is the width of the pillars base and $\mathrm{U}$ is the degree of undercut. For each run, 10 pillars were measured and the average of these was taken as the response value.

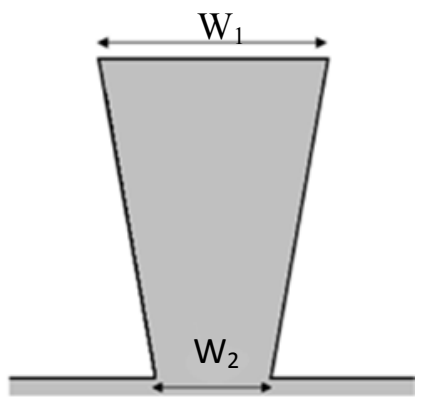

Figure 3, Schematic of pillar undercut

$$
\mathrm{W}_{1}-\mathrm{W}_{2}=\mathrm{U}
$$

The experimental data gathered was analysed using main-effects plots, Pareto charts and normal probability plots generated using Minitab®15.

\subsection{Experimental Procedure}

Silicon wafers underwent photolithography to pattern the wafer surface prior to DRIE. The photolithography process coated the wafer in a positive photoresist layer which was then exposed to UV light through a photomask. Areas of the photoresist which were exposed to UV light through gaps in the photomask were dissolved during development leaving areas of the wafer surface susceptible to etching during the DRIE process. Areas of the photoresist not exposed to UV light were not removed during development and acted as a protective layer from the etching process.

The wafers were first placed in a Polaron PT7160 RF plasma barrel etcher for a time of $120 \mathrm{~s}$, and then placed on a hotplate $\left(115^{\circ}\right)$ for $120 \mathrm{~s}$, to ensure the wafer surface was clean. The wafers were then placed in a hexamethyldisilazane environment for 15 minutes before being coated with S1818 positive photoresist in a spin-coater with a rotational speed of $4000 \mathrm{rpm}$ for a duration of $60 \mathrm{se}$. The wafers were then placed back on the hot-plate for $90 \mathrm{~s}$.

The wafers were placed in an MS56 mask aligner and exposed to UV light through a chrome-on-glass photomask, using a hard contact exposure programme, to pattern the resist surface with the features to be etched. Each wafer was exposed for 25 seconds.

The wafers were placed in a developer solution of MF319 for 25 seconds, and then rinsed in distilled and deionised water. 
The wafers were then placed back into the plasma barrel etcher for a further $120 \mathrm{~s}$.

A deep reactive ion etcher was used to process the experimental runs. Each run consisted of 100 cycles, and due to the various switching times not all runs took the same amount of time, Table 4.

\begin{tabular}{cccc}
\hline Run & Samples Name & Switching Time (s:s) & Total Run Duration (min) \\
\hline 1 & DOE 1 & $5: 5$ & $16: 45$ \\
\hline 2 & DOE 2 & $5: 5$ & $16: 45$ \\
\hline 3 & DOE 3 & $9: 5$ & $23: 29$ \\
\hline 4 & DOE 4 & $9: 5$ & $23: 29$ \\
\hline 5 & DOE 5 & $9: 5$ & $23: 29$ \\
\hline 6 & DOE 6 & $9: 5$ & $23: 29$ \\
\hline 7 & DOE 7 & $5: 5$ & $16: 45$ \\
\hline 8 & DOE 8 & $5: 5$ & $16: 45$ \\
\hline \multicolumn{4}{c}{ Table 4, Duration of each DRIE run }
\end{tabular}

The surface of each wafer was imaged, post etch, using an optical microscope. Wafers then underwent Oxygen plasma cleaning to remove any remaining photoresist, in order that the features could be examined in a field emission gun scanning electron microscope (SFEG-SEM). The conditions of cleaning are shown in Table 5.

Wafers were then re-examined using an optical microscope so a comparison of the features, pre and post Oxygen plasma cleaning, could be made. Upon comparison it was noted that there was no difference between the pre and post Oxygen plasma cleaned samples.

\begin{tabular}{cc}
\hline Pressure (mTorr) & 45.0 \\
\hline O2 Gas Flow (sccm) & 45 \\
\hline Coil Power $(\mathrm{W})$ & 800 \\
\hline Platen Power $(\mathrm{W})$ & 0 \\
\hline Cycle Time $(\mathrm{min})$ & 5 \\
\hline Table 5, $\mathrm{O}_{2}$ plasma cleaning Parameter settings
\end{tabular}

The pillar features on the wafer surfaces were imaged and examined using an SFEG-SEM. The width at the base and the apex of the pillars were measured and compared to determine the degree of undercut the features obtained in each DOE run using equation 1.

\subsection{Appearance of features}

\section{RESULTS}

Figures $4 \mathrm{a}$ and $4 \mathrm{~b}$ (run 3 and run 4 ) show examples of severe undercutting achieved on $5 \times 5 \mu \mathrm{m}$ features. The degree of undercut is such that no pillars could be observed standing on these samples. In contrast, figures $4 \mathrm{c}$ and $4 \mathrm{~d}$ (runs 1 and 2) show examples where the undercut is either positive or minimal.

Figures 5a to 5c (runs 2,1 and 8) show examples of uneven etching, where features are present between the pillars. For contrast an example of an evenly etched surface is shown in Figure 5d (run 7). A potential mechanism for the uneven etching observed for runs 2, 1 and 8 is the incomplete removal of the passivation layer during the etching phase. Residual particles of the passivation layer will act as randomly placed nano-scale masks resulting in the uneven etching pattern ${ }^{13 ;}$ ${ }^{14}$. In extreme cases this can result in the "black silicon" effect, shown in Figure 5 c (run 8 ) where the uneven etching of the surface has become gradually rougher through the etching cycles so that "black silicon" has been formed. ("Black silicon" is a needle-like surface structure comprised of silicon spikes which absorbs light reducing the reflective properties of the silicon surface ${ }^{14}$.) 
a)

c)

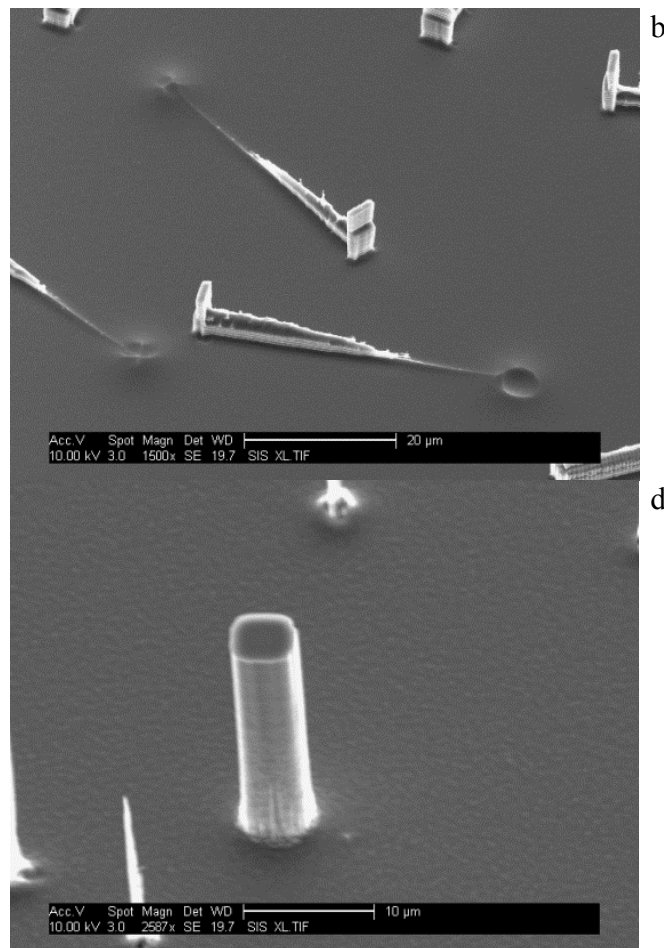

Figure 4, 5x5 4 m pillars, a) Run 3, b) Run 4, c) Run 1, d) Run 2

a)

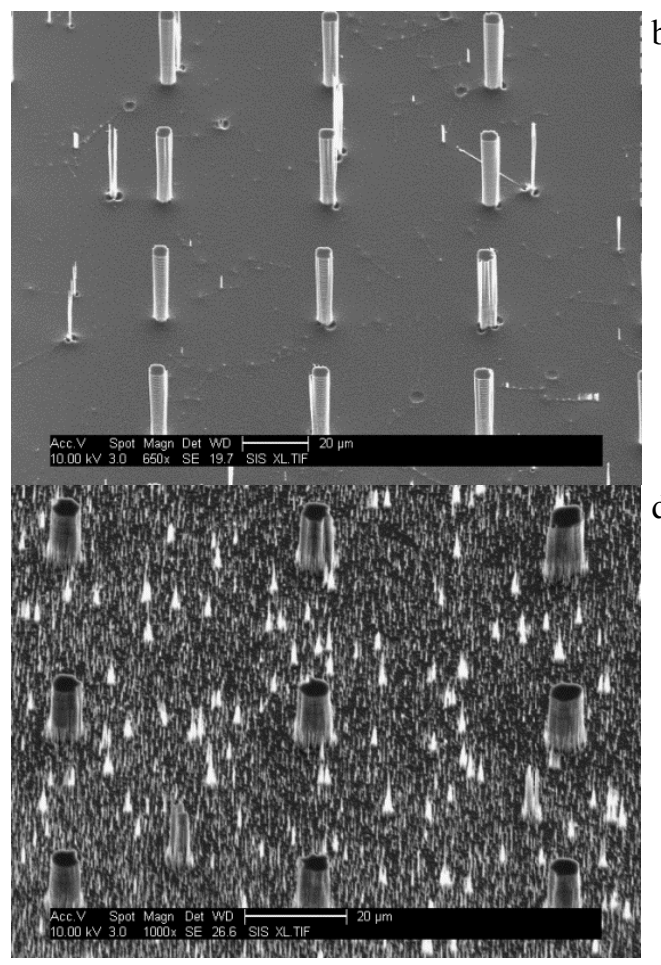

b)

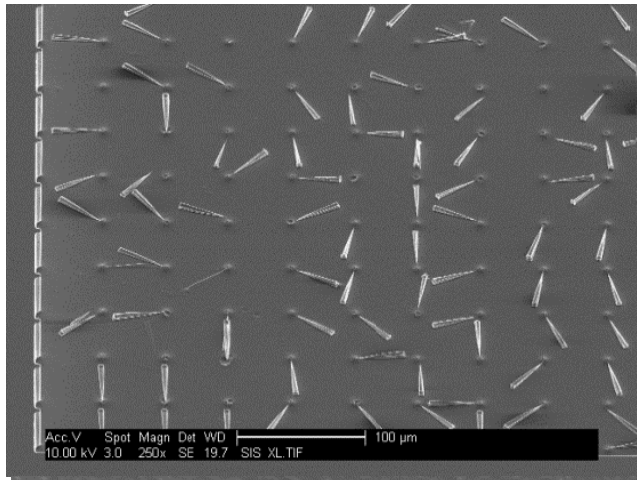

d)

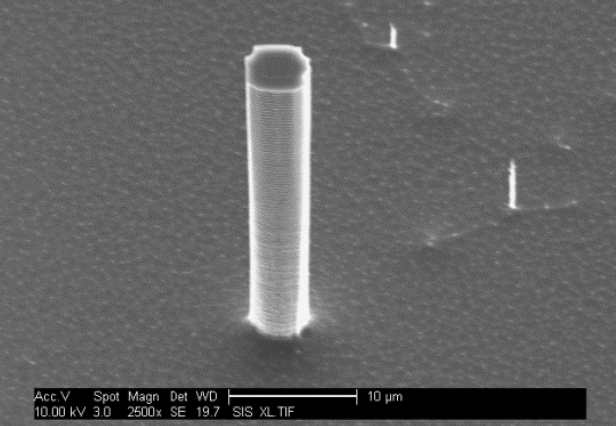

b)

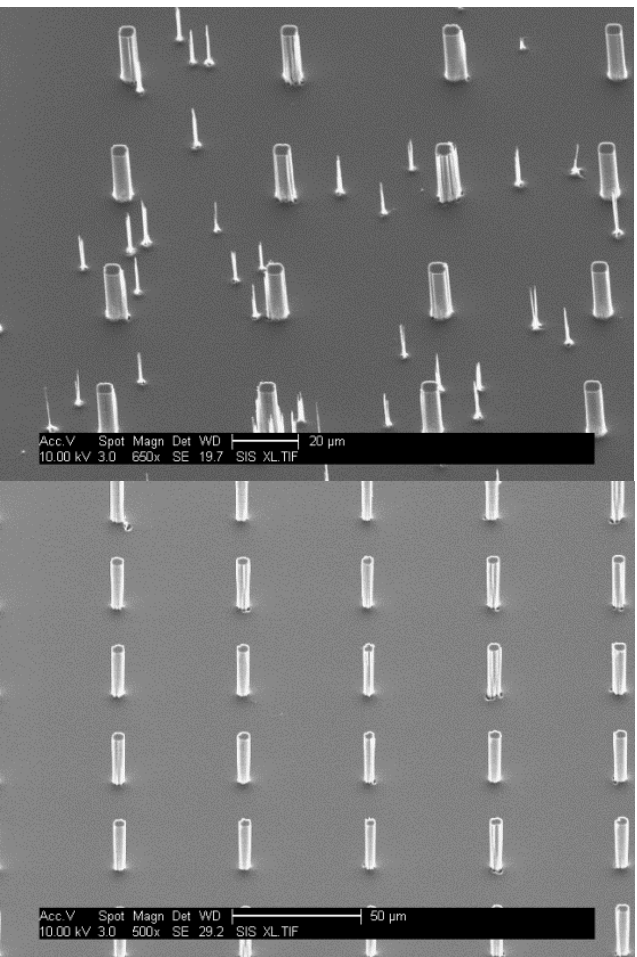

Figure 5, 5x5mm pillars, a) Run 2, b) Run 1, c) Run 8, d) Run 7 
Upon examination of the 10x10 $\mu \mathrm{m}$ features it was noted that incomplete etching of the wafer surfaces was observed for the same runs as those displayed for the $5 \times 5 \mu \mathrm{m}$ pillars. It should also be noted that the runs which resulted in the severely undercut $5 \times 5 \mu \mathrm{m}$ pillars also resulted in $10 \times 10 \mu \mathrm{m}$ pillars with large undercuts, although all the 10x10 $\mu \mathrm{m}$ pillars remained standing,

\subsection{Measured undercuts}

Table 6 shows the average undercut for the $10 \times 10 \mu \mathrm{m}$ and $5 \times 5 \mu \mathrm{m}$ pillars. None of the $2 \times 2 \mu \mathrm{m}$ pillars were successfully etched.

\begin{tabular}{|c|c|c|c|c|c|}
\hline \multirow{2}{*}{ Run } & \multirow{2}{*}{ Platen Power (W) } & \multirow{2}{*}{$\begin{array}{c}\mathrm{C}_{4} \mathrm{~F}_{8} \text { Gas Flow in Passivation } \\
\text { Stage (sccm) }\end{array}$} & \multirow{2}{*}{$\begin{array}{l}\text { Switching Times - Etching: } \\
\text { Passivation (s:s) }\end{array}$} & \multicolumn{2}{|c|}{$\begin{array}{c}\text { Undercut Averaged from } 10 \\
\text { pillars }\end{array}$} \\
\hline & & & & $10 \mathrm{x} 10 \mu \mathrm{m}$ & $5 \times 5 \mu \mathrm{m}$ \\
\hline 1 & - & + & - & 0.028 & -0.349 \\
\hline 2 & + & + & - & 0.354 & 0.441 \\
\hline 3 & - & + & + & 1.271 & - \\
\hline 4 & - & - & + & 1.572 & 3.986 \\
\hline 5 & + & - & + & 2.545 & - \\
\hline 6 & + & + & + & 1.800 & - \\
\hline 7 & + & - & - & 0.087 & 0.444 \\
\hline 8 & - & - & - & -0.729 & -1.091 \\
\hline
\end{tabular}

Table 6 , Average undercut for $10 \times 10 \mu \mathrm{m}$ and $5 \times 5 \mu \mathrm{m}$ Pillars

\subsection{Statistical analysis}

Figures 7-9 show the main-effects plots and Pareto charts for the $10 \times 10 \mu \mathrm{m}$ and $5 \times 5 \mu \mathrm{m}$ pillars.

Figures 6 and 8 are Pareto charts which display the significance of either an individual factor or of factor interactions using a bar chart. The bars are ordered in descending magnitude according to the effect on the response. The vertical line on the plot represents the point beyond which a factor becomes statistically significant; the value of alpha $(\alpha-0.05)$ indicates a chosen confidence limit of $95 \%$. The following symbols were used to represent the various factors on the Pareto charts: (A) platen power, (B) $\mathrm{C}_{4} \mathrm{~F}_{8}$ gas flow and (C) switching time.

Figures 7 and 9 are main-effects plots of each factor and display the factors' affect on the magnitude of the average undercut.

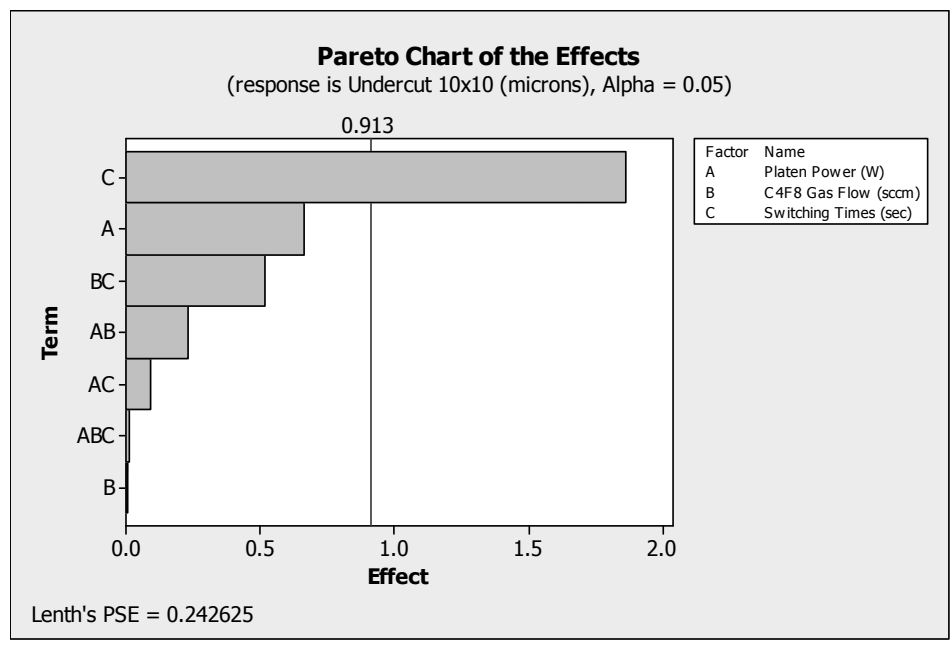

Figure 6, Pareto Chart for 10x10 $\mu \mathrm{m}$ pillars 


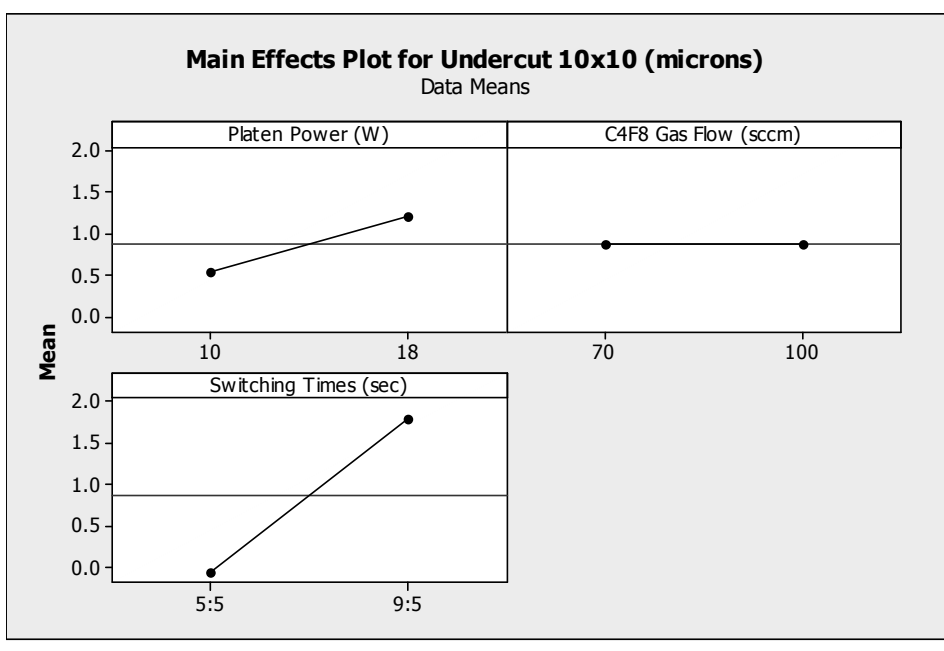

Figure 7, Main-Effects Plot for $10 \times 10 \mu \mathrm{m}$ pillars

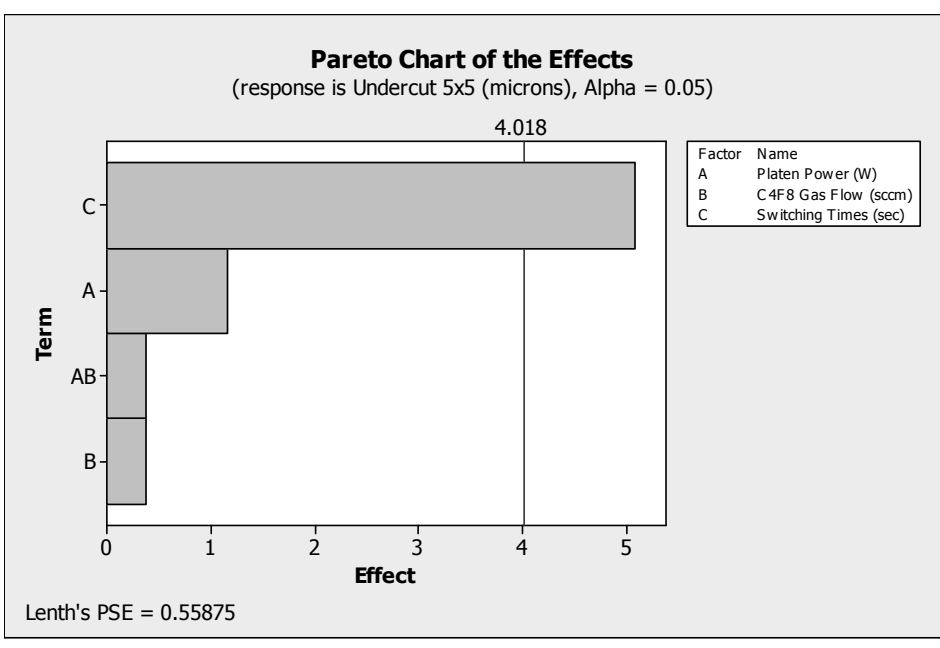

Figure 8 , Pareto Chart for $5 \times 5 \mu \mathrm{m}$ pillars

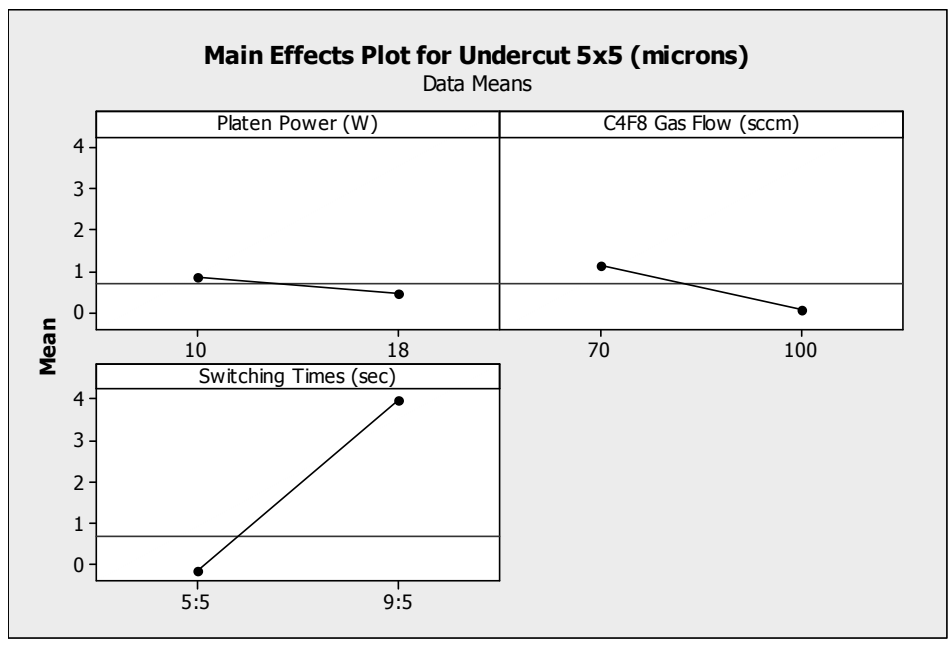

Figure 9, Main-Effects Plot for 5x5 $\mu \mathrm{m}$ pillars

Proc. of SPIE Vol. 8248 824808-8 


\section{DISCUSSION}

The $2 \times 2 \mu \mathrm{m}$ pillars were not successfully replicated. This is most likely due to the feature limitations of the photomask and the etching limitations of the DRIE.

For both the $5 \times 5 \mu \mathrm{m}$ and $10 \times 10 \mu \mathrm{m}$ pillars it was found that the switching time was the only statistically significant factor.

A possible mechanism for the observed significance of switching time is the rate at which the passivation layer is removed during the etching phase. The longer the etching phase the greater the silicon etch rate, which results in a more negative etch profile. Whereas for a shorter etching phase less time is available for the passivation layer to be completely removed prior to the silicon etching. This can result in an uneven etch surface and the black silicon effect.

\section{CONCULSIONS}

In this paper the effect of DRIE factors on feature undercut has been examined for three pillar dimensions: $2 \times 2 \mu \mathrm{m}, 5 \mathrm{x} 5$ $\mu \mathrm{m}$ and $10 \times 10 \mu \mathrm{m}$, using undercut as the measured experimental response.

A deign of experiment approach was used to evaluated the degree of feature undercut in correlation to the process factors. It was shown that switching times was the only statistically significant factor affecting the undercut of both $5 \times 5$ $\mu \mathrm{m}$ and $10 \mathrm{x} 10 \mu \mathrm{m}$ pillars. The $2 \mathrm{x} 2 \mu \mathrm{m}$ pillars were not successfully replicated.

\section{REFERENCE}

[1] Ayón, A. A., Braff, R., Lin, C. C., Sawin, H. H. and Schmidt, M. A. (1999), "Characterization of a time multiplexed inductively coupled plasma etcher", Journal of the Electrochemical Society, vol. 146, no. 1, pp. 339349.

[2] Evans, L.J. and Beheim, G.M., ( 2006), Deep reactive ion etching (DRIE) of high aspect ratio SiC microstructures using a time-multiplexed etch-passivate process, Pittsburgh, PA ed.

[3] MicroChemicals (2008), Lithography: Theory and Application of Photoresists, Developers, Solvents and Etchants, 2008/2009 ed, .

[4] Franssila, S. (2004), Introduction to Microfabrication, John Wiley \& Sons Ltd, Chichester.

[5] Beheim, G. M. and Evans, L. J. (2006), "Control of trenching and surface roughness in deep reactive ion etched 4H and 6H SiC", 2006 MRS Spring Meeting, Vol. 911, 18 April 2006 through 20 April 2006, San Francisco, CA, pp. 329.

[6] Wasilik, M. and Pisano, A. P. (2001), "Low frequency process for silicon on insulator deep reactive ion etching", in Chiao J.C., Faraone L., Barry Harrison H., et al (eds.), Device and Process Technologies for MEMS and Microelectronics II, Vol. 4592, 17 December 2001 through 19 December 2001, Adelaide, pp. 462.

[7] Nachmias, T., Ohayon, A., Melzer, S. E., Kabla, M., Louzon, E. and Levy, U. (2009), "Shallow Fresnel lens fabrication using grey scale lithography made by high energy beam sensitive mask (HEBS) technology and reactive ion etching", Advanced Fabrication Technologies for Micro/Nano Optics and Photonics II, Vol. 7205, 26 January 2009 through 28 January 2009, San Jose, CA, . 
[8] Guo, Y., Wang, Y., Sun, G. and Zhang, H. (2008), "Parameters extraction for DRIE model", 3rd IEEE International Conference on Nano/Micro Engineered and Molecular Systems, NEMS 2008, 6 January 2008 through 9 January 2008, Sanya, pp. 544.

[9] Held, J., Gaspar, J., Ruther, P., Hagner, M., Cismak, A., Heilmann, A. and Paul, O. (2008), "Systematic characterization of DRIE-based fabrication process of silicon microneedles", Microelectromechanical Systems Materials and Devices, Vol. 1052, 26 November 2007 through 28 November 2007, Boston, MA, pp. 271.

[10] Surface Technology Systems, Advanced Silicon Etch.

[11] Attia, U. M., Marson, S. and Alcock, J. R. (2009), "Micro-injection moulding of polymer microfluidic devices", Microfluidics and Nanofluidics, vol. 7, no. 1, pp. 1-28.

[12] Attia, U. M. and Alcock, J. R. (2009), "An evaluation of process-parameter and part-geometry effects on the quality of filling in micro-injection moulding", Microsystem Technologies, vol. 15, no. 12, pp. 1861-1872.

[13] Sun, G., Gao, T., Zhao, X. and Zhang, H. (2010), "Fabrication of micro/nano dual-scale structures by improved deep reactive ion etching", Journal of Micromechanics and Microengineering, vol. 20, no. 7.

[14] Jansen, H., De Boer, M., Legtenberg, R. and Elwenspoek, M. (1995), "The black silicon method: A universal method for determining the parameter setting of a fluorine-based reactive ion etcher in deep silicon trench etching with profile control", Journal of Micromechanics and Microengineering, vol. 5, no. 2, pp. 115-120. 
2012-12-31

\section{Design of experiment for the}

optimisation of deep reactive ion etching

of silicon inserts for micro-fabrication

Wallis, K.

SPIE

Wallis, K., Shaw, C. P., Alcock, J. R. (2012) Design of experiment for the optimisation of deep reactive ion etching of silicon inserts for micro-fabrication, Micromachining and Microfabrication

Process Technology XVII, San Francisco, California, USA, 24-26 January 2012

http://dx.doi.org/10.1117/12.906772

Downloaded from Cranfield Library Services E-Repository 